\title{
ICONOGRAFÍA DE SANTA WALDESCA Y SANTA TOSCANA, MONJAS DE LA ORDEN DE SAN JUAN DE JERUSALÉN, EN EL MONASTERIO DE SANTA MARÍA DE SIJENA ${ }^{1}$
}

\begin{abstract}
A lo largo de los siglos, en el monasterio de Santa María de Sijena, de la Orden de San Juan de Jerusalén, se tributó culto a dos santas de esta orden, Santa Waldesca o Ubaldesca y Santa Toscana. En este trabajo hacemos una aproximación a la iconografía de las mismas que hubo en ese monasterio.

Palabras clave: Iconografía; Santas; Orden de San Juan de Jerusalén; Monasterio de Santa María de Sijena.

For centuries, the cult of two saints belonging to the Order of Saint John of Jerusalem, Saint Waldesca or Ubaldesca and Saint Toscana was celebrated in the monastery of Santa María de Sijena. The author offers an approach to their iconography in this monastery.
\end{abstract}

Key words: Iconography; Saints; Order of St John of Jerusalem; Monastery of Saint Mary of Sijena.

El Real Monasterio de Santa María de Sijena, en la provincia de Huesca, fundado en 1188 por la reina doña Sancha, esposa de Alfonso II el Casto de Aragón, fue uno de los más importantes cenobios femeninos de la orden de San Juan de Jerusalén y atesoró a lo largo de su dilatada historia un rico patrimonio artístico. Sin embargo, poco de ello se conserva, pues gran parte se perdió en el incendio provocado por las tropas republicanas el día 8 de agosto de 1936, al que se dio inicio en la sillería coral en la iglesia, extendiéndose por la sala capitular y el resto del edificio conventual, no pudiéndose extinguir hasta una semana después. Las religiosas sanjuanistas regresaron a Sijena en febrero de $1946^{2}$.

Pocas son hoy las obras de arte que conserva este monasterio sanjuanista ${ }^{3}$, trasladadas a lo largo de las seis últimas décadas a otros lugares como el Museo de Zaragoza, el Museo de Huesca, el Museo Nacional de Arte de Cataluña y el Museo de Lleida Diocesano y Comarcal.

\section{Iconografía de Santa Waldesca y Santa Toscana, religiosas sanjuanistas ${ }^{4}$}

La atenta lectura de la bibliografía sobre Sijena nos permitió hallar, entre las numerosas imágenes existentes en el monasterio antes de la guerra civil, distintas referencias a la iconografía de dos santas sanjuanistas: Santa Waldesca o Ubaldesca ${ }^{5}$ y Santa Toscana.

Desde principios del siglo XVII y tras recibirse en el monasterio una reliquia de Santa Waldesca $^{6}$, tuvo ésta una capilla dedicada a su culto, con retablo, recinto que fue mandado construir por doña Serena de Moncayo, priora entre 1593 y 1608, cuyas armas (tres fajas de sable en campo de oro) figuraban en la misma.

La primera descripción de esta capilla nos la proporciona Mariano de Pano en 1882: "Capilla de Santa Waldesca. La oscuridad de su recinto no permite apreciar debidamente las pinturas que

\footnotetext{
${ }^{1}$ Este artículo forma parte del proyecto de investigación Arte y Órdenes Militares. Patrimonio de las órdenes de Jerusalén en España. Ref. HAR2008-00005.

2 Palacios SÁnchez, Juan-Manuel: Real Monasterio de Sijena. Memoria Historico-Descriptiva de los acontecimientos acaecidos desde el año 1936 a 1954, Gráficas Gracia, Calahorra, 1955.

${ }_{3}^{3}$ Desde 1985, abandonado por las monjas sanjuanistas, fue ocupado por una comunidad de las Hermanas de Belén y de la Asunción de la Virgen.

${ }^{4}$ Tenemos en preparación un estudio sobre la iconografía de los santos y beatos sanjuanistas en España.

5 De las dos maneras se le llama. Mantenemos aquí la denominación con la que se recoge su iconografía en la bibliografía consultada sobre Sijena.

${ }^{6}$ El 28 de mayo de 1587 el Gran Maestre de la Orden de San Juan de Jerusalén, Fr. Hugo de Loubenx Verdala, después de conseguir un Breve del papa Sixto V, de fecha 20 de septiembre de 1586, mandó trasladar parte de las reliquias de la santa a La Valeta. Posiblemente alguna de estas reliquias fue la que mandó al monasterio de Sijena.
} 
esconde ni ver con claridad los ricos florones de la bóveda. También esta capilla fue construida por orden de la ilustre Doña Serena de Moncayo, con ocasión de haberle remitido el Gran Maestre Lombex una reliquia de la Santa. Es el retablo de buena forma y consta de tres cuerpos. Presenta el del centro a Santa Waldesca, con aspecto muy agradable, de que también participan las efigies de uno y otro lado: San Juan Evangelista y San Lorenzo. Sobre éstos, en dos medallones, aparecen las cabezas de San Vicente Ferrer y Santo Domingo. Se ve en el remate y último cuerpo, la Venida de Nuestra Señora del Pilar. Tras las sacras, forman la base de todo el armazón tres pasajes de la vida de la santa titular, representando el del centro su ingreso en la Orden de San Juan. Bien merece este retablo ser observado detenidamente, así como también un cuadro colgado al exterior de la capilla, en el cual se ve el momento en que la Virgen y San Juan se aparecen a Santa Waldesca: ésta como religiosa de servicio que fue, tiene junto a sí una especie de caldera de cobre. La figura de la Virgen es muy linda; su cabeza, rodeada de ángeles, ostenta un tocado delicadísimo y ciñe la corona con igual gracia. Tanto las pinturas del altar como las del cuadro, ya bastante deterioradas, están hechas sobre tabla y parecen hijas del mismo pincel. Esta capilla tuvo en otro tiempo magnífica dotación de colgaduras, alhajas y ornamentos"

Igualmente hace Pano referencia a la reliquia de la santa que se encontraba en el relicario del coro: "De Santa Waldesca, religiosa que fue de la Orden de San Juan en el monasterio de San Cosme de la ciudad de Pisa, hay una costilla enviada a Doña Serena de Moncayo por el Cardenal Verdella o por el Gran Maestre Hugo de Lombex, que a los dos se atribuye"8.

Pocos años más tarde, en 1890, Javier Fuentes y Ponte describe así esta capilla: "Descendiendo a la planta baja o piso del claustro, inmediatamente a la izquierda de la salida de la puerta de la escalera, se halla una capilla, de planta casi cuadrada, con techo de poca altura que decoraron con florones; conservándose en las paredes los listonajes de madera, revelando, que se cubrían con ricas colgaduras y valiosos tapices: fue construida según las disposiciones de la Priora D. ${ }^{a}$ Serena de Moncayo para conmemorar que en 1600 el Gran Maestre Fr. Hugo de Lourbens de Verdalle le regalara una reliquia de Santa Waldesca religiosa sanjuanista a que la Priora dedicó dicha capilla. Es oscura y no es posible distinguir bien las pinturas de su retablo que distribuidas en tres cuerpos manifiestan en el centro la imagen de Santa Waldesca, y en los compartimentos de sus lados, las de S. Juan Bautista y S. Lorenzo mártir sobre las que aparecen dentro de medallones, los bustos de S. Vicente Ferrer y Santo Domingo de Guzmán, rematando la composición arquitectónica con la venida de la Virgen del Pilar como centro de un cuerpo decorado. En el zócalo hay tres asuntos de la Santa Religiosa siendo el central, su ingreso en la orden Sanjuanista"9.

También este autor describe la otra pintura que antes mencionábamos: "Fuera de la capilla se ve un cuadro representando a la Santísima Virgen y a San Juan apareciéndose a aquella religiosa de servicio, que tiene junto a ella una caldera o vasija grande de cobre, atributo con que los artistas la vienen representando siempre"10.

\footnotetext{
7 Pano, Mariano de: "Real Monasterio de Sijena", en Monserrat de Bondia, Sebastián y Pleyan de Porta, José: Aragón Histórico, Pintoresco y Monumental, t. I, Imprenta del Aragón Histórico, Zaragoza, s. a. [1882], pp. 160-161. El mismo texto se reproduce con escasísimas variantes en PANo y RuATA, Mariano de: Real Monasterio de Santa María de Sijena, edición coordinada por José Ángel Sesma Muñoz con textos introductorios de José Ángel Sesma Muñoz, Wifredo Rincón García, Juan Fernando Utrilla Utrilla y M. ${ }^{a}$ Carmen Lacarra Ducay, Caja Inmaculada, Zaragoza, 2004, pp. 159-160. En una nota del autor se indica que la pintura con la aparición de la Virgen y San Juan a la santa "ha pasado a una de las salas del Priorado. Allí se conservará mejor".

${ }^{8}$ PANO [1882], pp. 146-147 y PANO, 2004, p. 132.

9 Fuentes y Ponte, Javier: Memoria histórico-descriptiva del Santuario de Santa María de Sijena, 3 vols., Imprenta Mariana, Lérida, 1890, vol. II, p. 87.

${ }^{10}$ Fuentes y Ponte, 1890, vol. II, p. 87.
} 


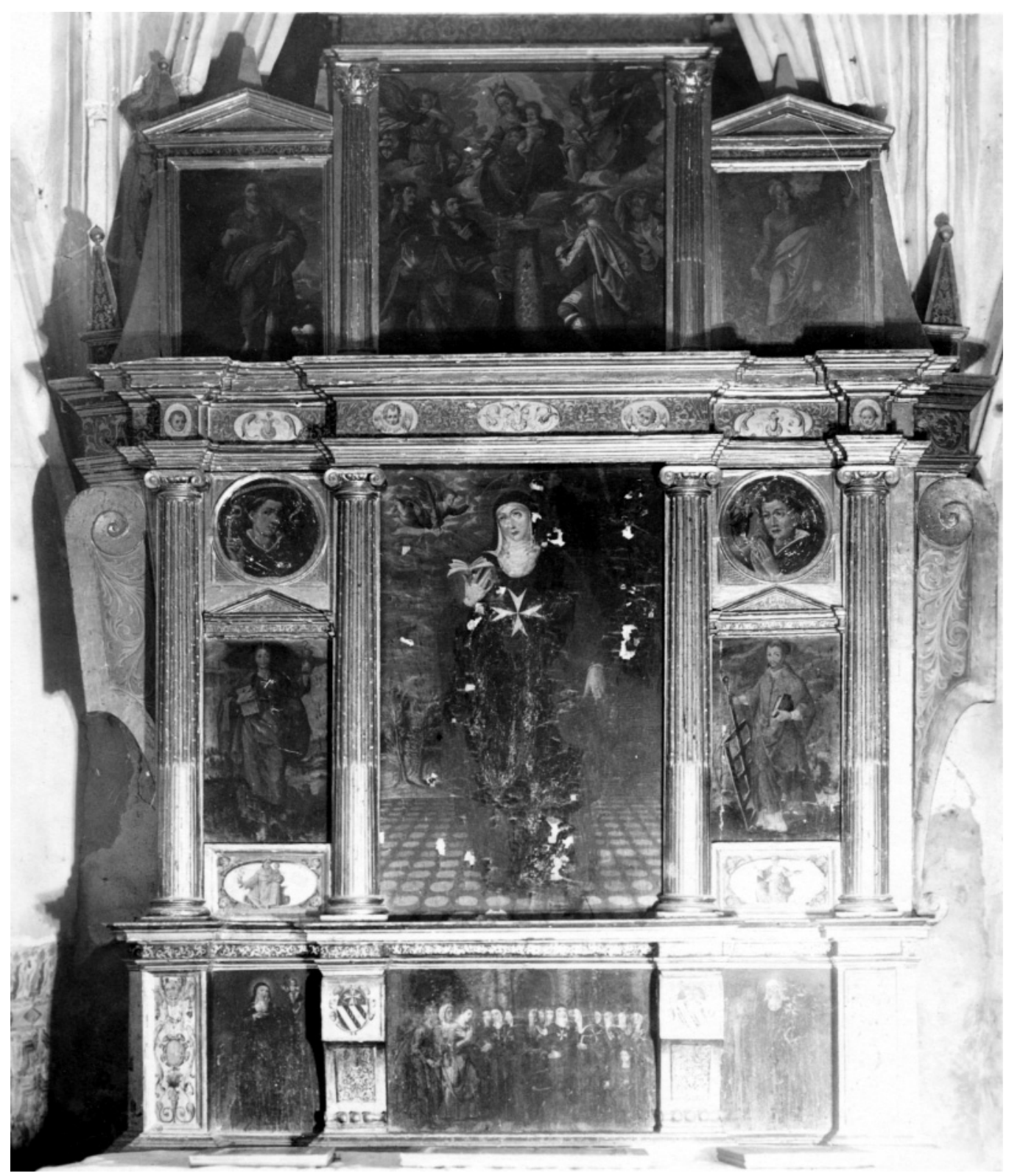

Fig. 1. ANÓNIMO: Retablo de Santa Waldesca en su capilla del monasterio de Sijena. (C)Archivo Fotográfico del Centro de Ciencias Humanas y Sociales. CSIC. 
Con anterioridad al texto que hemos transcrito sobre la capilla de la santa, este autor, al trazar la historia cronológica del monasterio ya se había ocupado de ella: "Capilla de Santa Waldesca. Era la priora doña Serena de Moncayo aficionada a mejorar la fábrica del monasterio, y habiendo llegado en su tiempo la reliquia de Santa Waldesca, regalada por el Gran Maestre Verdalle, proyectó e hizo en el claustro la capilla de Santa Waldesca en 1600, y a gran coste la adornó con colgaduras, alhajas y ornamentos" 11 .

La última descripción in situ de este retablo -que no aporta ningún dato nuevo de interés- se debe a Ricardo del Arco Garay, quien redactó la parte correspondiente a Huesca del Catálogo Monumental de España por Real Orden de 1 de agosto de 1920, aunque no fue publicado hasta 1942, "revisado y puesto al día", aunque en el caso del monasterio de Sijena mantuvo la redacción inicial, indicando el estado del cenobio antes del incendio de 1936 ${ }^{12}$. El mayor interés de esta publicación radica en la inclusión, en el volumen II, de una fotografía del retablo en su ubicación original, conservada en el archivo fotográfico del antiguo Instituto "Diego Velázquez" del CSIC y actualmente en la Unidad de apoyo y tratamiento archivístico del Centro de Ciencias Humanas y Sociales del CSIC (fig. 1), donde también se encuentra otra fotografía -creemos que inédita- de la pintura central de la predela, ahora en paradero desconocido, con la escena de la vida de la santa a la que se refieren todos los autores ${ }^{13}$.

De la tabla que colgaba en el exterior de la capilla, en el claustro, no tenemos ninguna noticia, pues no se sabe si fue destruida durante el incendio o trasladada a algunos de los lugares donde hemos mencionado se conservan obras procedentes de este monasterio. Por lo que respecta al retablo de Santa Waldesca, la mayor parte de sus tablas (Santa Waldesca, San Juan Evangelista, San Lorenzo, San Vicente Ferrer, Santo Domingo de Guzmán, San Juan Bautista, San Andrés, la Venida de la Virgen del Pilar a Zaragoza y Santa Gertrudis) se conservan en el Museo de Lleida Diocesano y Comarcal ${ }^{14}$.

De todas ellas nos interesa en estos momentos el estudio de la pintura de la santa titular, que centraba el retablo, restaurada en los últimos años ${ }^{15}$, que no figura en la exposición permanente del museo (fig. 2). Se trata de una pintura al óleo sobre tabla, en la que fue representada la santa pisana, de pie, en un interior, tal como se advierte por el suelo de azulejos con motivos geometrizados. Un cortinón de color verde, recogido en el lado derecho, deja ver un curioso paisaje de aspecto triste y desolador, en cuyo cielo aparece un ángel mancebo, volando, que trae a la santa la palma del triunfo. Viste Santa Waldesca como religiosa de la orden de San Juan de Jerusalén, con hábito negro, en el que destaca en el pecho, de gran tamaño, la cruz de la orden, en blanco, toca blanca y doble velo, uno blanco, en el interior, y otro negro en el exterior. Rodea su cabeza un nimbo de luz. Elevados los ojos hacia el cielo, tal vez hacia la visión del ángel que porta la palma, porta como atributos un libro en la mano derecha y en la izquierda un caldero de cobre con vino, recordando uno de sus milagros, cuando convirtió el agua en vino.

11 Fuentes y PONTE, 1890, vol. I, p. 75.

12 Arco y Garay, Ricardo del: Catálogo Monumental de España. Huesca, Consejo Superior de Investigaciones Científicas, Instituto Diego Velázquez, 2 vols., Madrid, 1942, vol. I, p. 407.

13 Agradecemos a Rosa María Villalón Herrera su colaboración para la localización de estas fotografías y su escaneado.

${ }^{14}$ De este retablo se ocupa Naval Mas, Antonio: Patrimonio emigrado, Gobierno de Aragón, Diario del Alto Aragón y Diputación de Huesca, Huesca, 1999, pp. 232-233.

15 Restaurada por Inma Bové Barberà, Obres restaurades al Museu de Lleida, Museu de Lleida Diocesà i Comarcal, Lleida, febrer 2001. Agradecemos la colaboración prestada por Carmen Berlabé y Alberto Velasco, conservadores del Museu de Lleida Diocesà i Comarcal a propósito de la pintura de Santa Waldesca conservada en este museo, al igual que por habernos proporcionado la fotografía que ilustra este artículo. 


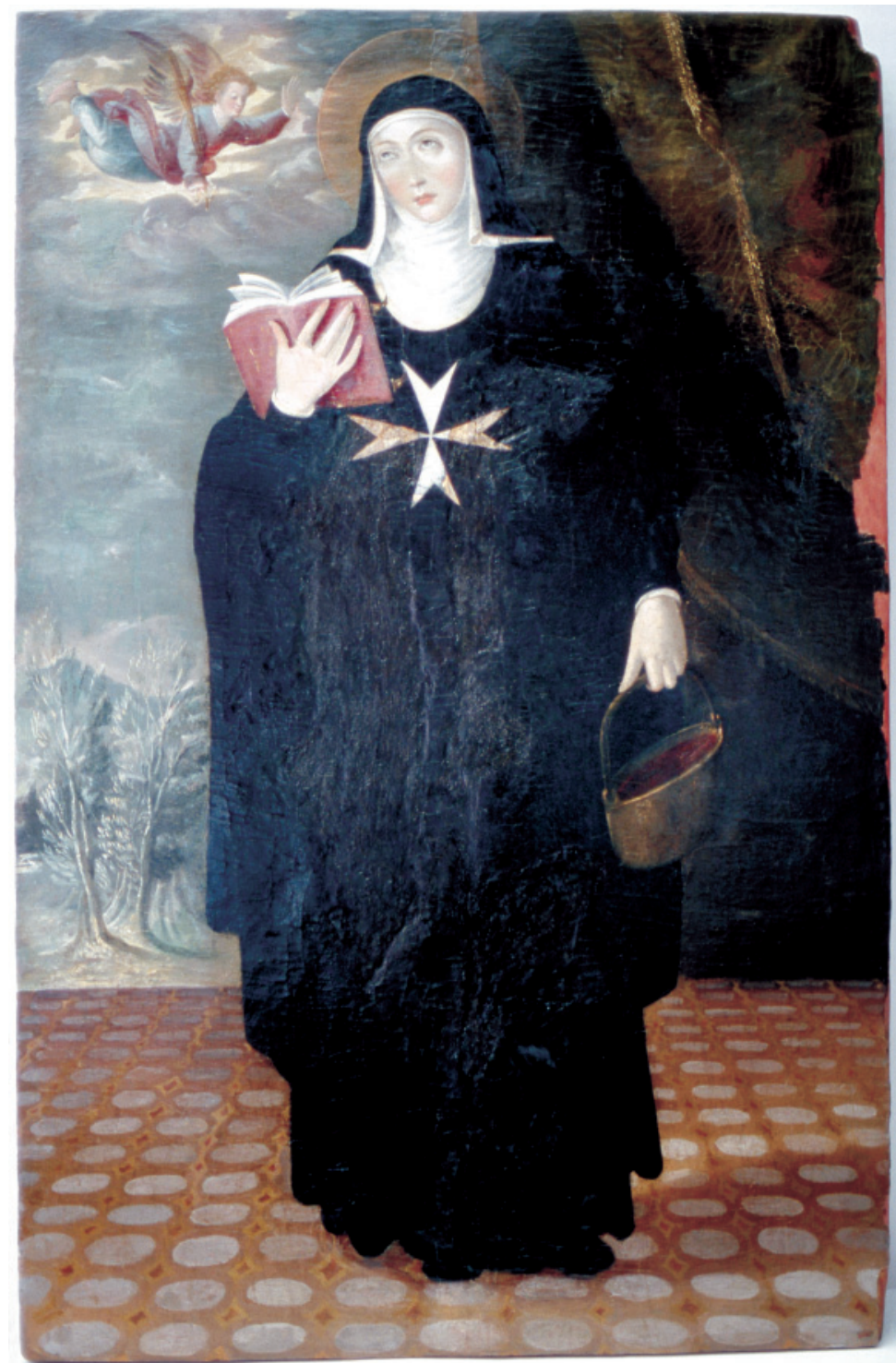

Fig. 2. ANÓNIMO: Santa Waldesca, óleo sobre tabla, Museo de Lleida Diocesano y Comarcal. CMuseu de Lleida: diocesà i comarcal.

En el mismo retablo, y tal como podemos ver en fotografías antiguas, se representaba en la tabla central de la predela una escena en la que aparece la comunidad del convento de Pisa saliendo a recibir a la joven Waldesca, tal como se recoge en las hagiografías de la santa. De esta pintura se desconoce su paradero (fig. 3).

Santa Waldesca Taccini o Ubaldesca nació en 1136 en Castelo de Calcinaia, en el condado de Pisa, en la Toscana, en el seno de una familia humilde. Muy devota desde su juventud, se caracterizó por la caridad hacia los pobres, pidiendo a Dios le indicara su camino. A los 14 años tuvo la visión de un ángel que le mandó se trasladase a Pisa para ingresar en el convento de la orden de San Juan de Jerusalén. Cuando junto con sus padres se aproximaba al convento sanjuanista, 


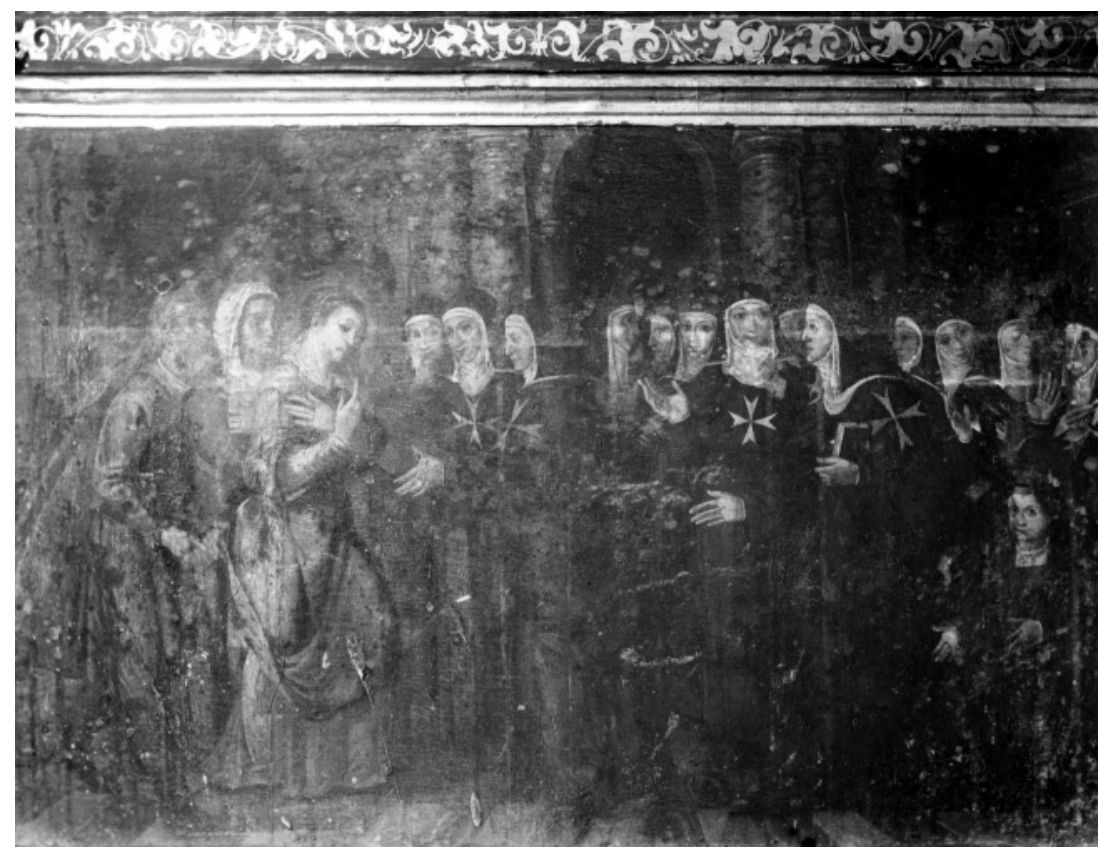

Fig. 3. ANÓNIMO: Santa Waldesca recibida a la puerta del convento por la comunidad sanjuanista de Pisa, paradero desconocido. (CArchivo Fotográfico del Centro de Ciencias Humanas y Sociales. CSIC.

toda la comunidad, con la abadesa -que había sido advertida de su llegada por un ángel- y los cuarenta religiosas que integraban la comunidad, salió a su encuentro a la puerta de la clausura, recibiéndola como religiosa. Allí vivió a lo largo de 55 años, hasta su fallecimiento el 28 de mayo de 1206, mortificando su cuerpo con prolongados ayunos y dedicada al ejercicio de la caridad sobre todo con los enfermos, obrando numerosos milagros que se multiplicaron tras su muerte. Destacaremos solamente uno de los milagros por la importancia que tiene para la iconografía de la santa. Un Viernes Santo una mujer, cansada por el trabajo, pidió a Santa Waldesca agua para no desfallecer, rogándole que antes la bendijera, a lo que al final accedió. Al probarla se dio cuenta que el agua se había convertido en vino. El recipiente se conservó durante varios siglos como una reliquia ${ }^{16}$.

La segunda de estas santas sanjuanistas es Santa Toscana, nacida en Cevio, cerca de Verona, hacia 1280. Desde muy joven dio muestras de su devoción y modestia, deseando permanecer virgen. Sin embargo al final aceptó contraer matrimonio con Alberto Canoculi, con quien se trasladó a vivir a Verona y con el que vivió en castidad y manteniendo sus devociones y las atenciones a los pobres, enfermos y desvalidos. Tras enviudar ingresó en el convento de religiosas de la orden de San Juan de Jerusalén de Verona, dedicada a la atención y a la ayuda a los demás, hasta su

16 Sobre la biografía de Santa Waldesca ver: CAturegli, Natale: "Ubaldesca, santa", Bibliotheca Sanctorum, Istituto Giovanni XXIII della Pontificia Università Lateranense, t. XII, Roma, 1969, pp. 731-732, con abundante bibliografía. También un libro español, Ruiz Lumbier, Fr. Juan: Espejo de vida y exercicios de virtud, para los devotos de la gloriosa virgen Santa Ubaldesca, abogada y conservadora del pan, vino y demás frutos de la tierra, Zaragoza, Herederos de Diego Dormer, 1686. En la p. 81 se recoge un Sermón de Santa Ubaldesca, de Antonio Iribarren. 


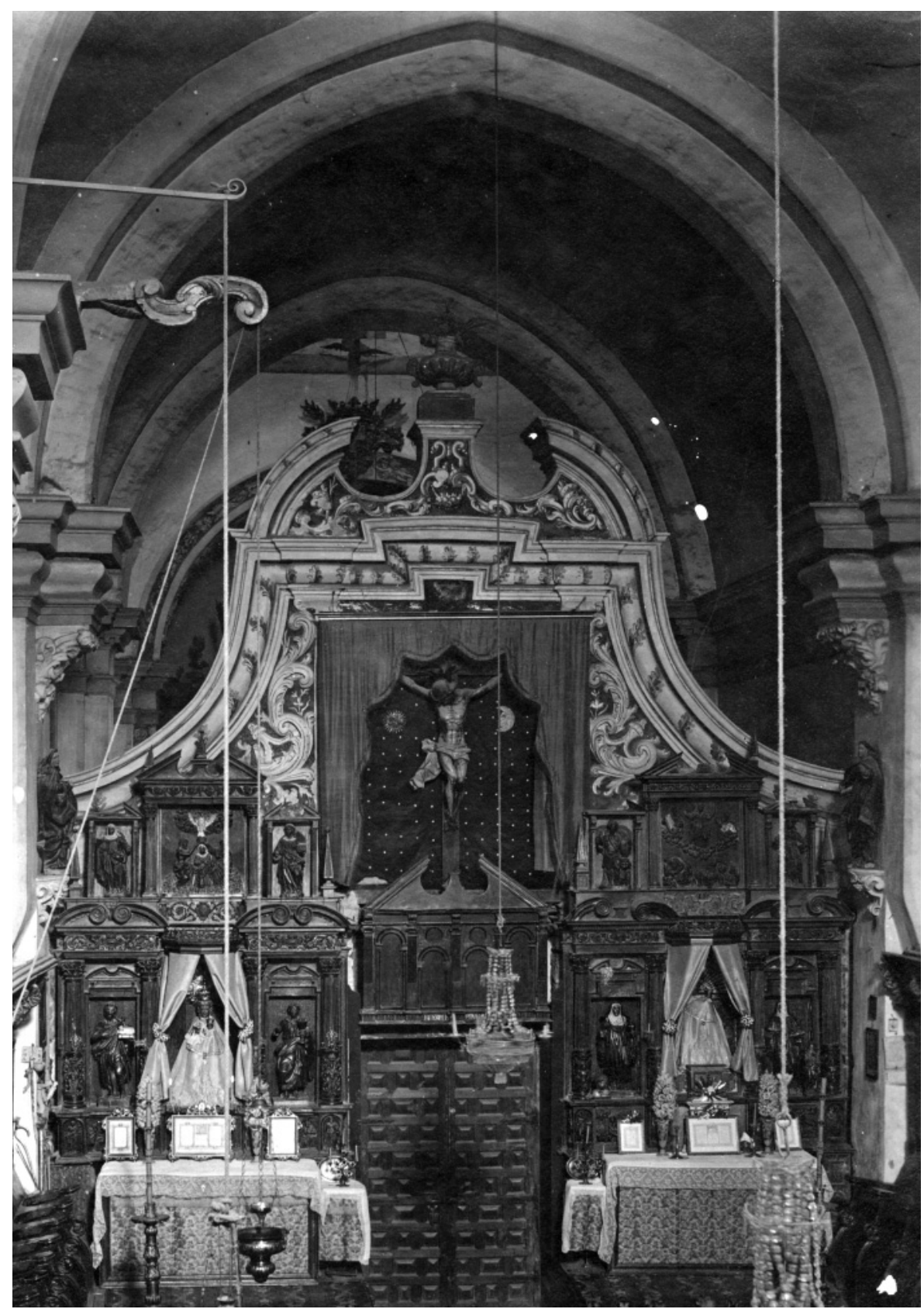

Fig. 4. Interior del coro del monasterio de Santa María de Sijena a principios del siglo XX. En el retablo del fondo, a la izquierda, en el segundo cuerpo puede advertirse la imagen de Santa Toscana y en los muros, las imágenes de Santa Waldesca y Santa Toscana. (C)Archivo Fotográfico del Centro de Ciencias Humanas y Sociales. CSIC. 
fallecimiento el 14 de julio de 1343 o 1344. Tanto durante su vida como después de su muerte, sus hagiógrafos recogen muchos milagros obrados gracias a su intercesión ${ }^{17}$.

Por lo que se refiere a la iconografía de Santa Toscana, Fuentes y Ponte al describir el retablo de la Virgen del Coro, en el interior del coro conventual cita una imagen de esta santa: "Sobre el cornisamiento general del primer cuerpo, se alzan a los lados estremos, dos romanatos dobles, o partidos en cada uno, y detrás de los mismos dos templetes con frontones triangulares y estatuas estando en el izquierdo la de Santa Toscana, religiosa Sanjuanista y en el derecho Santa Cecilia..." ${ }^{\prime 18}$. Efectivamente, en distintas fotografías de principios del siglo $\mathrm{XX}^{19}$ que reproducen el muro de separación del coro de las religiosas con la iglesia, con una puerta central -encima de la cual se encontraba el relicario- y dos retablos laterales, puede verse en el retablo de la izquierda, dedicado a la Virgen del Coro, en el segundo cuerpo -como describe Fuentes y Ponte-, y en el lado izquierdo, la imagen de Santa Toscana, con el hábito sanjuanista, cuya cruz se advierte en el pecho, con velo blanco sobre la toca (fig. 4).

De otras dos imágenes de estas santas da también noticias Fuentes y Ponte: "Destácanse asimismo de las paredes sobre las dos sillerías góticas de los lados unas estatuas modernas entre las que están Santa Waldesca, Santa Toscana, San Joaquín, San Cristobal y San Antonio"20.

En las mismas fotografías que antes mencionábamos pueden advertirse, en los laterales, junto al muro de cerramiento del coro y sobre ménsulas colocadas en la pared, dos imágenes de monjas sanjuanistas que, indudablemente, se trata de las que mencionaba Fuentes y Ponte. En ambos casos visten el hábito de la orden de San Juan de Jerusalén y parece tratarse de obras del siglo XVIII (vid. fig. 4).

Wifredo Rincón-García Instituto de Historia, CCHS, CSIC

\section{UNA APORTACIÓN A LA EBANISTERÍA GRANADINA EN LA SEGUNDA MITAD DEL SIGLO XIX*}

Una puerta de marquetería del museo Franz Mayer de México ha sido el hilo conductor para conocer la existencia de talleres granadinos de reproducciones e interpretaciones de mobiliario antiguo así como su exportación y éxito en el mercado internacional.

Palabras clave: Taracea; Juan Facundo Riaño; Rafael Contreras; Mueble español; siglo XVIII.

A marquetry door in the Franz Mayer Museum (Mexico) has served as the key for discovering the existence of $19^{\text {th }}$-century Granada furniture workshops where reproductions and interpretations of ancient pieces were made. They were widely disseminated and enjoyed great success on the international market.

Key words: Marquetry; Juan Facundo Riaño; Rafael Contreras; $18^{\text {th }}$ century; Spanish furniture.

La tradición de la taracea granadina de origen nazarí y su pujanza en la primera mitad del siglo XVI persistió en el buen hacer de los carpinteros granadinos a lo largo de los años, abierta

17 Sobre la biografía de Santa Toscana ver: GoRdinI, Gian Domenico: “Toscana, santa”, Bibliotheca Sanctorum, Istituto Giovanni XXIII della Pontificia Università Lateranense, t. XII, Roma, 1969, p. 719.

18 Fuentes y PONTE, 1890, vol. II, p. 61.

19 Una de ellas figura en el libro de PANO, 2004, p. 133 y la otra, en la Unidad de apoyo y tratamiento archivístico del Centro de Ciencias Humanas y Sociales del CSIC, que es la que hemos utilizado para ilustrar este artículo.

${ }^{20}$ Fuentes y Ponte, 1890, vol. II, p. 65.

* Este artículo se ha elaborado en el marco del proyecto de investigación «Los pavimentos marmóreos del Palacio Real de Madrid» (HUM 2006/6665). 